\title{
HUBUNGAN PELAKSANAAN BONDING DAN ATTACHMENT PADA IBU PRIMIPARA DENGAN REAKSI IBU DAN BAYI DI KAMAR BERSALIN RSUD POLEWALI MANDAR
}

Lina Fitriani \& Sri Wahyuni

Membentuk ikatan batin dengan bayi adalah : proses dimana hasil dari suatu interaksi terus menerus antara bayi dan orang tua (bayi dan anggota keluarga lain) dengan kedua pihak memainkan peran aktif, suatu hubungan yang bersifat saling mencintai dan mantap tercipta dan memberikan keduanya pemenuhan emosional, rasa percaya diri, stabilitas, hubungan yang bersifat saling membutuhkan (meskipun nantinya menjadi kemampuan untuk mandiri / independent dan kapasitas untuk meyadari potensi mereka dalam kehidupan). Tujuan Penelitian ini adalah untuk mempelajari Hubungan Pelaksanaan Boinding dan Attachment pada ibu primipara terhadap Reaksi Ibu dan Bayi di Kamar Bersalin RSUD Polewali Mandar. penelitian survey analitik dengan pendekatan cross sectional study. Tehnik sampel yang digunakan adalah Non Probability Sampling dengan metode Aksidental Sampling. Jumlah sampel yang didapatkan pada penelitian ini berjumlah 25 orang. Variabel independen adalah pelaksanaan bonding dan attachment, dan variabel dependen adalah reaksi ibu dan bayi. Data diolah secara univariat, dan bivariat dengan menggunakan Uji chi-square dengan tingkat kemaknaan $\alpha=0,5$ yang diolah dengan menggunakan softwere komputer. dengan menggunakan analisis fisher's exact test by chi square di dapatkan nilai $\mathrm{p}=0.012<\alpha$, artinya H0 ditolak yang berarti bahwa ada hubungan antara pelaksanaan bonding dan attachment dengan reaksi ibu dan bayi di Kamar Bersalin RSUD Polewali. Dari penelitian ini adalah ada pengaruh Bonding dan Atachment terhadap reaksi ibu dan bayi . sehingga perlu disarankan kepada petugas di kamar bersalin untuk selalu menerapkan tehnik Bonding dan Attachment

Kata Kunci $\quad$ : Bonding, Attachment, ikatan batin, kasih sayang ibu dan bayi.

Form a bond with the baby is: the process by which the result of an interaction continued menerus between baby and parents (infants and other family members) with the two parties play an active role, a relationship that is loving and steady created and give both emotional fulfillment, confidence, stability, a relationship that is interdependent (although later became the capacity for self / independent and recognizes the capacity for their potential in life). The purpose of this research is to study the implementation of Boinding and Attachment Relationships in primipara mothers against Reaction Mothers and Babies in Hospital Delivery Room Polewali. This research is analytic survey with cross sectional study. Sampling technique used is Non-Probability Sampling with accidental sampling method. The number of samples obtained in this study amounted to 25 people. The independent variable was the implementation of bonding and attachment, and the dependent variable is the reaction of the mother and baby. The data is processed using univariate and bivariate using chi-square test with significance level $\alpha=0.5$ which were processed using a computer softwere. The results of this study can be obtained using Fisher's exact test analysis by chi square at the get $\mathrm{p}=0.012<\alpha$, meaning that $\mathrm{H} 0$ rejected, which means that there is a relationship between the implementation of bonding and attachment by the reaction of mothers and babies at the Maternity Hospital Room Polewali. This study is no influence on 
the reaction atachment Bonding and mother and baby. so it was suggested to the officers in the delivery room to always apply the techniques Bonding and Attachment

Keywords : Bonding, Attachment, bonding, affectionate mother and baby.

\section{PENDAHULUAN}

Bonding adalah daya tarik awal dan dorongan untuk terjadinya ikatan batin antara orang tua dan bayinya. Bonding (ikatan batin) bukanlah suatu naluriah mengingat banyaknya laporan mengenai pembunuhan dan pelecehan terhadap bayi. Idealnya bayi dan anak yang tinggal bersama kedua orang tua kandungnya penuh dalam cinta dan harmoni, namun bayi / anak yang mempunyai problem keluarganya oleh perceraian orang tua (ibu / bapak) dan ibuibu yang belum berpengalaman adalah kenyataan kurang merasakan keharmonisan dalam keluarga.

Attachment adalah suatu perubahan perasaan satu sama lain yang paling mendasar ketika ada perasaan keterkaitan tanggung jawab dan kepuasan (Bobak, 2010). Membentuk ikatan batin dengan bayi adalah : proses dimana hasil dari suatu interaksi terus-menerus antara bayi dan orang tua (bayi dan anggota keluarga lain) dengan kedua pihak memainkan peran aktif, suatu hubungan yang bersifat saling mencintai dan mantap tercipta dan memberikan keduanya pemenuhan emosional, rasa percaya diri, stabilitas, hubungan yang bersifat saling membutuhkan (meskipun nantinya menjadi kemampuan untuk mandiri / independent dan kapasitas untuk meyadari potensi mereka dalam kehidupan).

Jumlah angka kematian ibu di Indonesia masih tergolong tinggi diantara negara-negara ASEAN lainnya. Menurut WHO pada tahun 2008 jika dibandingkan AKI Singapura adalah 6 per 100.000 kelahiran hidup, AKI Malaysia mencapai 160 per 100.000 kelahiran hidup. Bahkan AKI Vietnam sama seperti Negara Malaysia, sudah mencapai 160 per 100.000 kelahiran hidup, filipina 112 per 100.000 kelahiran hidup, brunei 33 per 100.000 per kelahiran hidup, sedangkan di Indonesia 228 per 100.000 kelahiran hidup. Menurut depkes pada tahun 2010, penyebab langsung kematian maternal di Indonesia terkait kehamilan dan persalinan terutama yaitu perdarahan $28 \%$. Sebab lain, yaitu eklampsi $24 \%$, infeksi $11 \%$, partus lama 5\%, dan abortus 5\%. (ASR Siringgo-Ringgo. 2012).

Angka Kematian Ibu (AKI) di Indonesia menurut Data SDKI pada tahun 2007 menunjukkan AKI sebesar 228/100.000 kelahiran hidup, sedangkan AKB sebesar 34/1000 kelahiran hidup. Jumlah kematian Ibu menurut provinsi di Indonesia diperkirakan mencapai 11.534 pada tahun 2010. Dari seluruh provinsi, Jawa Barat menduduki tempat pertama untuk jumlah kematian ibu, di ikuti oleh Provinsi Jawa Tengah, NTT, Banten dan Jatim. Bandingkan dengan Malaysia yang memiliki AKI 31 per 100.000 kelahiran hidup, Indonesia masih tertinggi. AKI di Indonesia sama dengan Myanmar yang kondisi negaranya jauh lebih miskin (Depkes, 2008).

Angka kematian ibu di Indonesia menurut survei demografi dan kesehatan Indonesia (SDKI) mencapai 307 dari 100.000 kelahiran hidup. Sedangkan pada tahun 2007 jumlahnya menurun menjadi 228 per 100.000 kelahiran hidup. Pemerintah khususnya Kementrian Kesehatan (Kemenkes) masih dituntut 
bekerja keras menurunkannya hingga tercapai target Millennium Development Goal (MDG)'5, menurunkan AKI menjadi 102 dari 100.000 pada tahun 2015. Tingginya Angka Kematian Ibu (AKI) ini tidak terlepas dari masih tingginya angka kehamilan yang tidak diinginkan yaitu mencapai 16,8 \% (SDKI, 2009).

Di Provinsi Sulawesi Barat terdiri atas lima Kabupaten, yaitu Kabupaten Mamuju, Kabupaten Mamasa, Kabupaten Majene, Kabupaten Polewali Mandar, dan Kabupaten Mamuju Utara. Faktor yang paling berhubungan terhadap pelayanan kesehatan di Sulawesi Barat adalah masih banyaknya daerah yang sulit dijangkau yang disebabkan oleh medan yang berat yang diantarai oleh daerah sungai dan hanya bisa dilalui dengan mengendarai kuda, disamping itu masih terdapat sekelompok masyarakat terasing yang masih menutup diri dari kemajuan ilmu dan pengetahuan (Arali, 2011).

Berdasarkan Data Laporan Profil Kesehatan Provinsi Sulawesi Barat, dimana pada Kabupaten Polewali Mandar tercatat jumlah kelahiran hidup sebanyak 7.204 dengan jumlah kematian ibu sebanyak 17 orang, pada Kabupaten Mamasa tercatat jumlah kelahiran hidup sebanyak 1.635 dengan jumlah kematian ibu sebanyak 9 orang, pada Kabupaten Mamuju Utara tercatat jumlah kelahiran hidup sebanyak 2.037 dengan jumlah kematian ibu sebanyak 8 orang, pada Kabupaten Majene tercatat jumlah kelahiran hidup sebanyak 3.198 dengan jumlah kematian ibu sebanyak 9 orang, pada Kabupaten Mamuju tercatat jumlah kelahiran hidup sebanyak 4.951 dengan jumlah kematian ibu sebanyak 15 orang.

Pada data diatas yaitu jumlah kematian ibu pada Kabupaten yang ada di Propinsi Sulawesi Barat dan jumlah kelahiran hidup yang diambil dari Data Profil Kesehatan Propinsi Sulawesi Barat Tahun 2009, secara absolute terlihat Kabupaten Polewali Mandar adalah jumlah kematian ibu yang paling tinggi (17 kematian ibu) dan yang terendah adalah Kabupaten Mamuju Utara (8 kematian Ibu) serta jumlah total kematian ibu untuk propinsi Sulawesi Barat adalah 58 Kematian. (Profil Dinkes Sulbar 2011).

Berdasarkan data yang diperoleh dari RSUD Polewali, tercatat jumlah pasien yang bersalin di ruang nifas pada tahun 2013 tercatat 95 pasien, sedangkan pada tahun 2014 tercatat jumlah pasien yang bersalin sebanyak 320. Jumlah pasien yang dirawat pada tahun 2015, dari bulan januari sampai desember 2015 tercatat jumlah pasien yang bersalin di nifas sebanyak 257 orang.

Berdasarkan survey awal yang saya lakukan di ruang kamar bersalin RSUD Polewali Mandar dimana pelaksanaan Bonding dan Attachment di rumah sakit sebagian kecil penolong persalinan telah melaksanakan, tetapi belum maksimal karena belum mengetahui pasti pelaksanaan Bonding dan Attachment.

Sehubungan dengan hal tersebut di atas, maka peneliti tertarik untuk mengadakan penelitian tentang "Hubungan Pelaksanaan Bonding dan Attachment pada Ibu Primipara terhadap Reaksi Ibu dan Bayi di Kamar Bersalin RSUD Polewali Mandar".

\section{METODELOGI PENELITIAN}

Desain penelitian adalah sesuatu yang sangat penting dalam penelitian, yang memungkinkan pemaksimalan kontrol beberapa faktor yang bisa memhubungani akurasi suatu hasil (Nursalam, 2011).

Metode atau desain yang digunakan dalam penelitian ini adalah desain penelitian cross sectional yang meruapakan rancangan penelitian yang pengukuran atau 
pengamatannya dilakukan secara simultan pada satu saat (sekali waktu) (Hidayat, 2007).

Populasi merupakan seluruh subjek atau objek dengan karakteristik tertentu yang akan diteliti. Bukan hanya objek atau subjek yang dipelajari saja tetapi seluruh karakteristik atau sifat yang dimiliki subjek atau objek tersebut (Hidayat, 2007).

Yang menjadi populasi dalam penelitian ini adalah semua ibu primipara yang dirawat inap di ruang kamar bersalin RSUD Polewali Kab. Polewali Mandar yaitu sebanyak 257 orang pada tahun 2015.

\section{Distribusi responden berdasarkan Umur Responden} Tabel 4.1 Distribusi Responden Berdasarkan Umur Responden Di Ruang Kamar Bersalin

\begin{tabular}{|c|c|c|c|}
\hline No & \multicolumn{1}{|c|}{ Umur } & $\mathbf{n}$ & \% \\
\hline $\mathbf{1}$ & $<20$ Tahun & 8 & 32.0 \\
\hline $\mathbf{2}$ & $20-35$ Tahun & 16 & 64.0 \\
\hline $\mathbf{3}$ & $>35$ Tahun & 1 & 4.0 \\
\hline & Total & $\mathbf{2 5}$ & $\mathbf{1 0 0 \%}$ \\
\hline
\end{tabular}

Sumber : Data Primer 2016

Berdasarkan tabel 4.1 diatas menunjukkan distribusi responden berdasarkan umur responden dimana usia < 20 tahun sebanyak $8(32,0 \%)$ orang, umur

2. Distribusi responden berdasarkan Pendidikan Responden Tabel 4.2 Distribusi Responden Berdasarkan Responden Di Ruang Kamar Bersalin

\begin{tabular}{|c|c|c|c|}
\hline No & Pendidikan & n & \% \\
\hline $\mathbf{1}$ & S D & 4 & 16.0 \\
\hline
\end{tabular}

20 - 35 tahun sebanyak $16(64,0 \%)$ orang, dan umur > 35 tahun sebanyak $1(4,0 \%)$ orang.
Sampel merupakan bagian populasi yang akan diteliti atau sebagian jumlah dari karakteristik yang dimiliki oleh populasi

\section{HASIL DAN PEMBAHASAN}

Hasil

Analisa univariat ini bertujuan memenuhi distribusi frekuensi dari variabel dependen yaitu reaksi ibu dan bayi. 


\begin{tabular}{|c|c|c|c|}
\hline $\mathbf{2}$ & SLTP & 8 & 32.0 \\
\hline $\mathbf{3}$ & S M A & 12 & 48.0 \\
\hline $\mathbf{4}$ & AKADEMI / PT & 1 & 4.0 \\
\hline & Total & $\mathbf{2 5}$ & $\mathbf{1 0 0 \%}$ \\
\hline
\end{tabular}

Sumber : Data Primer 2016

Berdasarkan tabel 4.2 tersebut $(48,0 \%)$ orang, SLTP sebanyak $8(32,0 \%)$ menunjukkan distribusi responden berdasarkan pendidikan responden dimana pendidikan tertinggi yaitu SMA sebanyak 12

orang, SD sebanyak $4(16,0 \%)$, dan AKADEMI/PT sebanyak $1(4,0 \%)$ orang.

3. Distribusi responden berdasarkan Pekerjaan Responden Tabel 4.3 Distribusi Responden Berdasarkan Pekerjaan Responden Di Ruang Kamar Bersalin

\begin{tabular}{|c|l|c|c|}
\hline No & \multicolumn{1}{|c|}{ Pekerjaan } & n & \% \\
\hline $\mathbf{1}$ & I R T & 12 & 48.0 \\
\hline $\mathbf{2}$ & Swasta & 4 & 16.0 \\
\hline $\mathbf{3}$ & Wiraswasta & 7 & 28.0 \\
\hline $\mathbf{4}$ & P N S & 2 & 8.0 \\
\hline & Total & $\mathbf{2 5}$ & $\mathbf{1 0 0 \%}$ \\
\hline
\end{tabular}

Sumber : Data Primer 2016

Berdasarkan tabel 4.3 diatas menunjukkan distribusi responden berdasarkan pekerjaan responden dimana pekerjaan tertinggi yang dilakukan responden yaitu IRT sebanyak $12(48,0 \%)$ orang, Wiraswasta sebanyak $7 \quad(28,0 \%)$

4. Distribusi responden berdasarkan Pelaksanaan Bonding dan Attachment Tabel 4.4 Distribusi Responden Berdasarkan Pelaksanaan Bonding dan Attachment di Ruang Kamar Bersalin

\begin{tabular}{|c|l|c|c|}
\hline No & \multicolumn{1}{|c|}{$\begin{array}{c}\text { Pelaksanaan Bonding dan } \\
\text { Attachment }\end{array}$} & n & \% \\
\hline $\mathbf{1}$ & Dilaksanakan & 19 & 76.0 \\
\hline $\mathbf{2}$ & Tidak Dilaksanakan & 6 & 24.0 \\
\hline
\end{tabular}




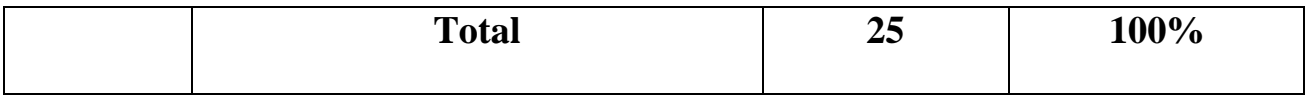

Sumber : Data Primer 2016

Berdasarkan tabel 4.4 tersebut dilaksanakan sebanyak $19 \quad(76,0 \%)$ menunjukkan distribusi responden berdasarkan pelaksanaan bonding dan responden, dan kategori tidak dilaksanakan sebanyak $6(24,0 \%)$ responden.

attachment responden dimana pada kategori

5. Distribusi responden berdasarkan Reaksi Ibu dan Bayi Tabel 4.5 Distribusi Responden Berdasarkan Reaksi Ibu dan Bayi di Ruang Kamar Bersalin

\begin{tabular}{|c|c|c|c|}
\hline No & Dukungan Suami & $\mathbf{n}$ & $\%$ \\
\hline 1 & Positif & 16 & 64.0 \\
\hline 2 & Negatif & 9 & 36.0 \\
\hline & Total & 25 & $100 \%$ \\
\hline
\end{tabular}

Sumber : Data Primer 2016

Berdasarkan tabel 4.5 diatas menunjukkan distribusi responden berdasarkan reaksi ibu dan bayi dimana kategori tertinggi yaitu positif dalam reaksi ibu dan bayi sebanyak $16(64,0 \%)$ orang, dan kategori negatif dalam reaksi ibu dan bayi sebanyak $9(36,0 \%)$ orang.

Analisa Bivariat

Analisa bivariat digunakan untuk menguji hubungan variabel Independent

yaitu pelaksanaan bonding dan attachment dengan reaksi ibu dan bayi di kamar bersalin.

Uji Statistik yang digunakan adalah analisis Chi-Square dengan tingkat kemaknaan $\alpha<0,05$. Maka ketentuan pelaksanaan bonding dan attachment dengan reaksi ibu dan bayi dikatakan mempunyai hubungan yang sangat bermakna bila pvalue $<0,05$

1. Hubungan Pelaksanaan Bonding dan Attachment dengan Reaksi Ibu dan Bayi Tabel 4.6 Hubungan Pelaksanaan Bonding dan Attachment dengan Reaksi Ibu dan Bayi di Kamar Bersalin RSUD Polewali

\begin{tabular}{|c|c|c|c|c|c|}
\hline & \multicolumn{2}{|c|}{ Reaksi Ibu dan Bayi } & \multirow[t]{2}{*}{ Total } & \multirow[t]{2}{*}{$P$} \\
\hline & & Positif & Negatif & & \\
\hline \multirow[t]{2}{*}{$\begin{array}{l}\text { Pelaksanaan Bonding } \\
\text { dan Attachment }\end{array}$} & $\begin{array}{l}\text { Dilaksanakan } \\
\%\end{array}$ & $\begin{array}{c}15 \\
60.0\end{array}$ & $\begin{array}{c}4 \\
16.0\end{array}$ & $\begin{array}{c}19 \\
76,0\end{array}$ & \multirow{3}{*}{$\begin{array}{c}0, \\
01 \\
2\end{array}$} \\
\hline & $\begin{array}{l}\text { Tidak } \\
\text { Dilaksanakan } \\
\%\end{array}$ & $\begin{array}{c}1 \\
4.0\end{array}$ & $\begin{array}{c}5 \\
20.0\end{array}$ & $\begin{array}{c}6 \\
24.0\end{array}$ & \\
\hline \multicolumn{2}{|c|}{ Total } & $\begin{array}{c}16 \\
64.0\end{array}$ & $\begin{array}{c}9 \\
36.0\end{array}$ & $\begin{array}{l}25 \\
100\end{array}$ & \\
\hline
\end{tabular}

Sumber : Data Primer 2016 
Berdasarkan tabel 4.6 diatas, didapatkan bahwa pelaksanaan bonding dan attachment dengan reaksi ibu dan bayi di Kamar Bersalin RSUD Polewali tertinggi pada kategori pelaksanaan bonding dan attachment dilaksanakan dengan reaksi positif sebanyak $15(60,0 \%)$ responden. Dan terendah pada kategori pelaksanaan bonding dan attechment tidak dilakukan dengan reaksi positif sebanyak $1(4,0 \%)$ responden.

Dengan menggunakan analisis fisher's exact test by chi square di dapatkan nilai $\mathrm{p}=0.012<\alpha$, artinya H0 ditolak, ada hubungan antara pelaksanaan bonding dan attachment dengan reaksi ibu dan bayi di Kamar Bersalin RSUD Polewali.

\section{Pembahasan}

1. Pelaksanaan Bonding dan Attachment

Berdasarkan hasil penelitian pada tabel 4.4 tersebut menunjukkan distribusi responden berdasarkan pelaksanaan bonding dan attachment responden dimana pada kategori dilaksanakan sebanyak 19 (76,0\%) responden, dan kategori tidak dilaksanakan sebanyak $6(24,0 \%)$ responden.

Teori dr Hamilton MP mengatakan bahwa sikap yang diperlihatkan oleh petugas kesehatan yang memberikan bayi kepada orang tua dan perasaan ibu yang ingin melihat bayi baru lahir. Reaksi bonding ibu pada 15 responden yang tidak diberi perlakuan, hasil baik 0 responden $(0 \%)$ dan hasil buruk 15 responden (100\%). Hasil buruk karena ibu masih berkonsentrasi pada rasa sakit yang dirasakan oleh kelelahan.

Ikatan batin diawali oleh rasa kasih sayang terhadap bayi. Bayi-bayi yang menderita karena diabaikan, rasa jemu atau kecemasan, tidak merasa cukup aman untuk membentuk suatu ikatan batin dengan orang tua. Tetapi, terbentuk bukan hanya karena bayi diberi makan dan dimandikan saja atau hanya merespon kebutuhan - kebutuhan mendasar dari bayi, proses ikatan batin tak akan berlangsung. Ikatan batin terjadi bila orang tua belajar untuk peka bahkan terhadap sinyal-sinyal yang paling halus, seperti ekspresi wajah, gerakan tangan dan melakukan sesuatu.

Cara terbaik untuk membentuk ikatan dengan bayi adalah memperlihatkan secermat mungkin apa yang dikatakan melalui "bahasa tubuh" selain memberikan respon terhadap tanda-tanda yang lebih nyata sifatnya, seperti tangisan atau degukan. (Bobak, 2010).

\section{Reaksi Ibu dan Bayi}

Berdasarkan hasil penelitian pada tabel 4.5 menunjukkan distribusi responden berdasarkan reaksi ibu dan bayi dimana kategori tertinggi yaitu positif dalam reaksi ibu dan bayi sebanyak $16(64,0 \%)$ orang, dan kategori negatif dalam reaksi ibu dan bayi sebanyak $9(36,0 \%)$ orang.

Sejak bayi dilahirkan, bayi sudah memiliki kemampuan sensoris yang mengindikasikan kesiapan untuk berinteraksi dengan sosial. Bayi dapat menggunakan respon perilaku secara efektif dalam melakukan dialog pertama mereka.

\section{Hubungan Pelaksanaan Bonding dan Attachment dengan Reaksi Ibu dan Bayi \\ Berdasarkan hasil tabulasi silang} pada tabel 4.6, didapatkan bahwa pelaksanaan bonding dan attachment dengan reaksi ibu dan bayi di Kamar Bersalin RSUD Polewali tertinggi pada kategori pelaksanaan bonding dan attachment dilaksanakan dengan reaksi positif sebanyak $15(60,0 \%)$ responden. Dan terendah pada kategori pelaksanaan bonding dan attechment tidak dilakukan dengan reaksi positif sebanyak $1(4,0 \%)$ responden.

Dengan menggunakan analisis fisher's exact test by chi square di dapatkan 
nilai $\mathrm{p}=0.012<\alpha$, artinya $\mathrm{H} 0$ ditolak, ada hubungan antara pelaksanaan bonding dan attachment dengan reaksi ibu dan bayi di Kamar Bersalin RSUD Polewali.

Teori Bobak (2010) mengemukakan bahwa ada pengaruh Bonding dan Attachment yang dilakukan oleh petugas kamar bersalin dengan melakukan interaksi awal antara ibu dengan bayi segera setelah lahir, sehingga terjadi ikatan batin (Bonding) dan kasih sayang (Attachment).

Peranan perawat sangatlah penting dimana perawat mempunyai tanggung jawab terhadap individu secara menyeluruh atau holistik. Dalam teori holistik seluruh organisme hidup saling berinteraksi dimana terjadi gangguan pada satu bagian maka akan mempengaruhi yang lain salah satunya adalah tindakan yang dilaksanakan oleh penolong persalinan dengan meletakkan bayi pada perut ibu segera setelah lahir bertujuan untuk melakukan interaksi awal antara ibu dan bayi pada setiap ibu melahirkan normal sehingga terjadi ikatan batin dan kasih sayang. Oleh karena itu sangatlah penting kiranya bagi petugas kamar bersalin untuk memberikan penjelasan tentang Bonding dan Attachment sehingga terjadi interaksi antara ibu dengan bayi segera setelah lahir.

\section{KESIMPULAN DAN SARAN Kesimpulan}

Berdasarkan hasil penelitian dan pembahasan maka peneliti mengambil kesimpulan sebagai berikut :

Pelaksanaan Bonding dan Attachment pada ibu primipara dimana pada kategori dilaksanakan sebanyak $19 \quad(76,0 \%)$ responden, dan kategori tidak dilaksanakan sebanyak $6(24,0 \%)$ responden. Reaksi Ibu dan Bayi diaman dimana kategori tertinggi yaitu positif dalam reaksi ibu dan bayi sebanyak $16(64,0 \%)$ orang, dan kategori negatif dalam reaksi ibu dan bayi sebanyak 9 $(36,0 \%)$ orang. Adanya hubungan pelaksanaan bonding dan attachment pada ibu primipara dengan reaksi ibu dan bayi di kamar bersalin RSUD Polewali dengan nilai p-value 0,012 yang berarti bahwa H0 ditolak dan H1 diterima.

Saran

Perlunya pembuatan prosedur tetap tentang Bonding dan Attachment dikamar bersalin RSUD Polewali, dan memberikan pelatihan bagi petugas kamar bersalin mengenai pelaksanaan Bonding dan Attachment.

Perlunya dukungan dari Kepala Badan Pengelola Rumah Sakit khususnya bagian kebidanan dan kandungan tentang pelaksanaan Bonding dan Attachment. Bagi yang berminat meneliti topik yang sama, sebaiknya meneliti ibu yang Multipara dengan jumlah populasi yang lebih banyak tanpa membatasi status, pendidikan dan ekonomi sebagai pembanding dalam penelitian ini.

\section{DAFTAR PUSTAKA}

Arali.(2009).http://arali2008.files.wordpress. com/2008/08/asia_2010-kesehatanfinal.pdf. (Online) diakses tanggal 8 Februari 2016.

ASR Siringgo-Ringgo. 2012. Hubungan pengetahuan ibu hamil dan motivasi keluarga terhadap pelaksanaan antenatal care. (Online). http://jurnal.usu.ac.id/index.php/jkh/ article/download/317/191. Diakses tanggal 8 Februari 2016.

Bobak, I.M., dkk. (2010). Buku Ajar Keperawatan Maternitas . Edisi IV. Cetakan I. Bandung: Yayasan Ikatan Alumni Pendidikan Keperawatan Padjajaran 
Bowel, (2008). Perawatan Maternitas dan Ginekologi .Bandung: Yayasan Ikatan Alumni Pendidikan Keperawatan Padjajaran

Depkes RI (2008). Pedoman Pelayanan Antenatal di Tingkat Pelayanan Dasar Puskesmas. Jakarta: Pusdiknakes.

2011. Pedoman Pemantaaun Wilayah Setempat Kesehatan Ibu dan Anak. Jakarta : Direktorat Jenderal Bina Kesehatan Keluarga.

Depkes RI. 2008. Pusat Data dan Informasi Kementrian Kesehatan Indonesia. http://www.depkes.go.id (Online) diakses tanggal 8 Februari 2016.

Hidayat, A. Aziz Alimul. 2007. Riset Keperawatan dan Teknik Penulisan Ilmiah. Jakarta : Salemba Medika.

Lawrence. 2010. Konsep Dasar Primigravida. (Online) http://by-one.blogspot.com /2010/07/konsepdasar-primigravida.html? $\mathrm{m}=1$. Diakses pada tanggal 8 Februari 2016.

Niven N. (2002). Psikologi Kesehatan.

Jakarta : EGC.

Niven. 2011. Psikologi Kesehatan : Pengantar Untuk Perawat Dan Profesional. Jakarta: EGC. (Online) http://drsuparyanto.blogspot.com/2010/10/k onsep-kepatuhan-1.html Diakses pada tanggal 8 Februari 2016.

Nursalam. 2011. Konsep dan Penerapan Metodologi Penelitian Ilmu Keperawatan: Pedoman Skripsi, Tesis dan Instrumen Penelitian
Keperawatan. Edisi Kedua. Jakarta: Salemba Medika.

Pate. 2010. Sinopsis Obstetri dan Operatif. Jakarta: EGC Saryono. (2008). Metodologi Penelitian Kesehatan. Mitra Cendekia, Yogyakarta.

Profil Dinas Kesehatan Sulbar. (2009). Data Dinas Kesehatan Sulawesi Barat (online). http://depkes.go.Id (diakses 8 Februari 2016)

Rubin. 2011. Buku Panduan Praktis Pelayanan Kesehatan Maternal dan Neonatal. Jakarta : Yayasan Bina pustaka.

SDKI (Survey Demografi Kesehatan Indonesia). 2009. (Online) http://www.litbang.depkes.go.id/site s/download/buku_laporan/lapnas_ris kesdas_SDKI_2009/Laporan_riskes das_2009.pdf. Diakses pada tanggal 8 Februari 2016.

Wahab, A, 2012. Pengantar Riset (Bidang Kesehatan, Kebidanan dan Keperawatan). Yogyakarta : Kutub Wacana. 
